\title{
Article \\ A Proposed Uncertainty Reduction Criterion of Renewable Energy Sources for Optimal Operation of Distribution Systems
}

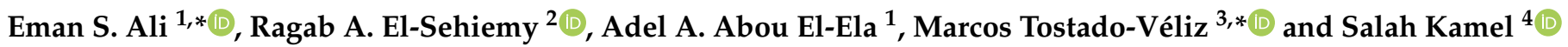 \\ 1 Electrical Engineering Department, Faculty of Engineering, Menofia University, Shebin El-Kom 32511, Egypt; \\ adel.aboalella@sh-eng.menofia.edu.eg \\ 2 Electrical Engineering Department, Faculty of Engineering, Kafrelsheikh University, \\ Kafrelsheikh 33511, Egypt; elsehiemy@eng.kfs.edu.eg \\ 3 Electrical Engineering Department, University of Jaen, 23071 Jaen, Spain \\ 4 Electrical Engineering Department, Faculty of Engineering, Aswan University, Aswan 81542, Egypt; \\ skamel@aswu.edu.eg \\ * Correspondence: eman_salah@sh-eng.menofia.edu.eg (E.S.A.); mtostado@ujaen.es (M.T.-V.)
}

Citation: Ali, E.S.; El-Sehiemy, R.A.; Abou El-Ela, A.A.; Tostado-Véliz, M.; Kamel, S. A Proposed Uncertainty Reduction Criterion of Renewable Energy Sources for Optimal Operation of Distribution Systems. Appl. Sci. 2022, 12, 623. https:// doi.org/10.3390/app12020623

Academic Editor: Muhammad Aziz

Received: 2 December 2021

Accepted: 5 January 2022

Published: 10 January 2022

Publisher's Note: MDPI stays neutral with regard to jurisdictional claims in published maps and institutional affiliations.

Copyright: (C) 2022 by the authors. Licensee MDPI, Basel, Switzerland. This article is an open access article distributed under the terms and conditions of the Creative Commons Attribution (CC BY) license (https:// creativecommons.org/licenses/by/ $4.0 /)$.

\begin{abstract}
Power system operation and planning studies face many challenges with increasing of renewable energy sources (RESs) penetration. These challenges revolve around the RESs uncertainty and its applications on probabilistic forecasting, power system operation optimization and power system planning. This paper proposes a novel and effective criterion for uncertainties modeling of the RESs as well as system loads. Four sorting stages are applied for the proposed uncertainty cases reduction. Added to that, it proposes three different uncertainty reduction strategies for obtaining different accuracy and speed options. The proposed reduction strategies are tested on medium and large scale distribution systems; IEEE 69-bus and 118-bus systems. The obtained results verify the effectiveness of the proposed criterion in uncertainties modeling in distribution systems with acceptable level of accuracy.
\end{abstract}

Keywords: unbalanced power flow; radial distribution system; distribution system analysis; uncertainty

\section{Introduction}

Currently, many electrical power system studies are concerned with uncertainty modeling especially those which based on renewable energy sources (RES) such as photovoltaic (PV) and wind turbines (WT). Due to the uncertainty nature of RES, their output powers are basically depending on the climatic conditions such as solar irradiance $(\mathrm{G})$, temperature (T) and wind speed (VW) [1]. Neglecting uncertainties related to the renewable generation and load demand results in getting solution for the power system problems away from reality [2]. So that, the need for appropriate and accurate RES uncertainty modelling become a must in many research fields like RES planning [3], micro-grids management [4,5], RES integration analysis [6,7], and power system reliability analysis [8]. Therefore, there are various methodologies for uncertainty modeling and analysis in power systems.

The most common uncertainty analysis methods are:

- Probabilistic methods: used when the historical data is available. It can be divided into numerical and analytical approaches [9].

- Possibilistic methods [10]: used when the historical data is unavailable. it can be divided into defuzzification method and alpha-cut method.

- Combined possibilistic and probabilistic methods [11]: these methods mix between the features of the possibilistic and probabilistic methods such as possibilistic-Monte Carlo approach.

Monte Carlo simulation (MCS) is one of the most popular numerical uncertainty approaches [12]. In [9], authors were applied MCS to simulate RES uncertainty during their integration in distribution grids. However, the accuracy of MCS, it is a time consumer. So 
that, Pseudo-sequential Monte Carlo (PSMC) simulation was introduced to reduce the time consumed. In [13], reliability risk analysis of renewable based distribution systems was presented using PSMC. In [14], PSMC was integrated in an optimization based technique to achieve the system reliability beside obtaining economic benefits. Authors in [15], analyzed the uncertainty of the WT output using probability density function (PDF) to regulate the system voltage using optimization based method. In [16], uncertainties related to PV and WT were modeled using Gram-Charlier series for developing a fast power flow technique. In [17], a hybrid point estimation and MCS method were presented for large scale WT simulation in a transmission expansion planning issue. In [18], to determine the generation system adequacy, a possibilistic model was presented for simulating uncertainty of WTs power generation. there are some uncertainties that can not be modeled possibilistically or probabilistically, a hybrid method can be used combining the merits of the two techniques [19]. However, the hybrid technique is a time consuming more than any of the other techniques. In [20], the optimized uncertainty modeling is considered in the case of lack of data. In probabilistic method, with huge data, the complexity of the problem makes the simulation time too long and in some application it became unsolvable [21]. Therefore, there is a need for simplifying or reducing the uncertainty modeling complexity. In [22], the probability density function was partitioned into a number of states for representing WT uncertainty. where, increasing the number of states increases the problem complexity but it also enhances the modeling accuracy. In [23], a scenario based uncertainty modeling is utilized for uncertainty reduction of both WT and system loads though hosting capacity maximizing problem. In [24], The uncertainty of two wind profile and system load demand is simplified and modeled using three dimension scenarios based probabilistic method. In [25], a reduced set of scenarios were introduced for representing the uncertainties of WT, PV and load demand in optimal planning of active distribution grids. On the other hand, worst case scenario was utilized for getting conservative solutions in RES integration problems [26]. Also, worst case scenario uncertainty based model was incorporated with robust control problem of RES [27]. The main issue of the pre-mention uncertainty reduction studies is that it considered as a trade-off problem because the modelling accuracy is inversely proportional to the time consumed [28]. Therefore with reducing the uncertainty complexity, the simulation accuracy decreases and the computational error increases.

In this paper, a novel uncertainty cases reduction criterion is proposed for modeling the uncertainties of two types of RES (PV and WT) besides the distribution system loads uncertainty. The proposed criterion can be applied further for other uncertainty quantities. Three different strategies are introduced for offering different degrees of simplicity and accuracy depending on the considered uncertainty cases.

\section{RESs Uncertainty}

Two categories of RESs in distribution systems are considered, i.e., wind turbines (WT) and photovoltaic (PV) modules, which are considered as the sources of uncertainties in distribution systems.

\subsection{WT Modeling}

The output power of WT depends on the value of wind speed $\left(V_{w}\right)$. It can be calculated from the following equation [29]:

$$
P_{w}\left(V_{w}\right)= \begin{cases}P_{\text {rated }} \frac{\left(V_{w}-V_{c i}\right)}{\left(V_{r}-V_{c i}\right)} & V_{c i} \leq V_{w} \leq V_{r} \\ P_{\text {rated }} & V_{r} \leq V_{w} \leq V_{c o} \\ 0 & \text { otherwise }\end{cases}
$$

where $P_{w}$ refers to wind turbine output power. $V_{r}$ is the rated wind speed of the WT. $V_{c i}$ and $V_{c o}$ are the cut-in and cut-out wind turbine speeds. 


\subsection{PV Modeling}

\subsubsection{Accurate PV Modeling}

There several models that are presented in the literature to model the PV cell and modules as [30-34]. Among these models, the double diode model of the PV cell in Figure 1 presents an accepted accurate compared with single diode model in $[35,36]$. PV output power depends on solar irradiance $(\mathrm{G})$ and ambient temperature $(\mathrm{T})$.

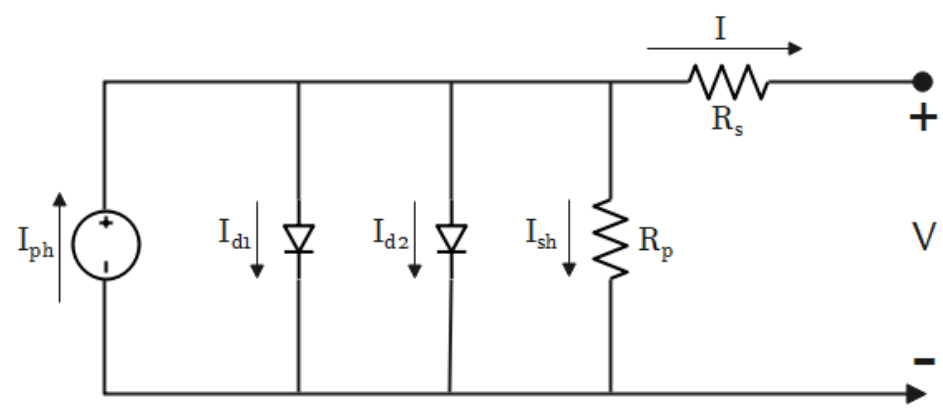

Figure 1. Photo Voltaic cell model.

The relation between the cell voltage and current can be obtained from the following [37]:

$$
I=I_{p h}-I_{s h}-I_{d 1}-I_{d 2}
$$

where,

$$
\begin{gathered}
I_{p h}=\frac{G}{G_{S T C}} \times\left(I_{p h_{S T C}}+\alpha_{I_{S c}} \Delta T\right) \\
I_{s h}=\frac{V+R_{S} I}{R_{P}} \\
I_{d 1}=I_{S 1}\left(e^{\frac{\left(q\left(V+R_{S} I\right)\right.}{a_{1} K T}}-1\right) \\
I_{d 2}=I_{S 2}\left(e^{\frac{\left(q\left(V+R_{S} I\right)\right.}{a_{2} K T}}-1\right)
\end{gathered}
$$

where, $I_{p h}$ is the photo-generated current, $I_{S 1}$ and $I_{S 2}$ are the reverse saturation current for the first and second diodes, respectively. $R_{P}$ and $R_{S}$ are the cell shunt and series resistance. $q$ and $K$ are referring to the electron charge and the Boltzmann Constant respectively. $a$ is the diode ideality factor. T refers to ambient temperature. STC refers to the standard conditions $\left(G_{S T C}=1 \mathrm{~kW} / \mathrm{m}^{2}, T_{S T C}=25^{\circ} \mathrm{C}\right)$.

For a certain climate conditions, PV module output power can be calculated by forming the $(\mathrm{I}-\mathrm{V})$ characteristic curve and obtaining the point of maximum power from the curve. Each point in the curve is calculated by solving Equstion (2) at a certain voltage. The maximum power point is chosen as the operating point.

\subsubsection{Approximate PV Modeling}

Various studies simplified the $P V$ calculations by ignoring the effect of the ambient temperature by considering the solar irradiance only. The $P V$ output power $\left(P_{P V}\right)$ can be calculated as the following equation:

$$
P_{P V}(G)= \begin{cases}\frac{P_{r} G^{2}}{G_{s t d} G_{C}} & 0 \leq G \leq G_{C} \\ \frac{P_{r} G}{G_{s t d}} & G_{C} \leq G\end{cases}
$$

where, $P_{r}$ refers to $P V$ plant rated power. $G_{\mathcal{C}}$ The cut-in value of the solar irradiance $\left(0.12 \mathrm{~kW} / \mathrm{m}^{2}\right)$ [38]. The approximate $P V$ modeling is used in fast and simplified studies as in Ref. [38], but ignoring the effect of the ambient temperature causes a percent of error in 
$P V$ output calculations. This error may reach to $30 \%$ as in Figure 2 . This figure is obtained by using the approximate $P V$ modeling and the accurate $P V$ modeling in calculating the output power from a certain $P V$ module under a certain environment conditions for one day $(24 \mathrm{~h})$.

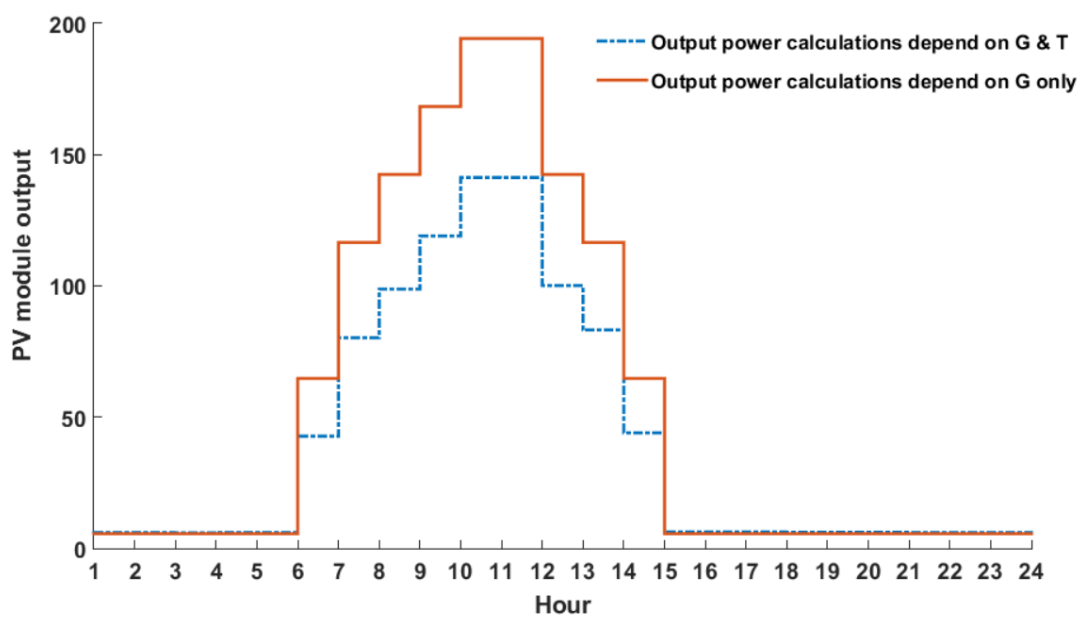

Figure 2. PV output power for one day by using the approximate PV modeling and the accurate PV modeling.

\section{Proposed Reduction Criteria for RESs Uncertainty}

Considering a large number of uncertainty cases may cause a very long computation time and sometimes will result in no solution for the problems. Thus, considering hourly historical data for one year results in 8784 uncertainty cases that are responsible for complexing the problem, especially when there is a need for doing power flow calculations for each uncertainty case. Therefore, there is a need for reducing the number of uncertainty cases without losing accuracy. In this paper, four stages are proposed to reduce the uncertainty cases as follows:

\section{- First Stage}

1. Establishing the base matrix that consists of 8784 rows and 4 columns; the rows represent the year hours, and the columns represent the uncertainty parameters $\left(G, T, V_{W}, L R\right)$.

2. All the matrix row values are rearranged according to the $G$ values when it is arranged in ascending order.

3. Forming the $\mathrm{G}$ sub-groups as follows: $\mathrm{G}$ sub-groups are the groups which are formed by dividing the practical irradiance range into three equal sub-groups limited by four boundaries $\left(G_{0}, G_{1}, G_{2}, G_{M}\right)$ as shown in Figure 3, where $G 0$ is the lowest practical solar irradiance, $G_{M}$ is the highest practical solar irradiance, $G_{1}$ is the boundary between the first and second sub-groups, and $G_{2}$ is the boundary between the second and third sub-groups. The values of $G_{1}$ and $G_{2}$ are calculated as shown in Figure 3.

4. Using the formed sub-groups to divide the base matrix into three sub-matrices (M1, M2, M3), where each sub-group forms a sub-matrix.

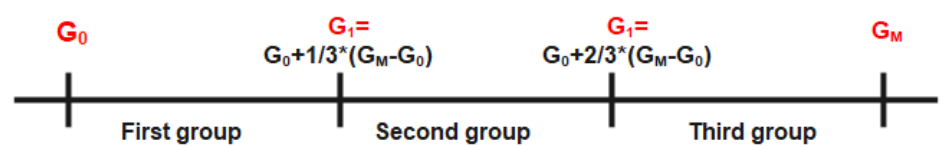

Figure 3. Sub-group formation according to $G$ values. 


\section{- Second Stage}

1. Rearrange the rows of the sub-matrices $\left(M_{1}, M_{2}, M_{3}\right)$ according to the values of $\mathrm{T}$ in ascending order.

2. Follow the sub-grouping technique used in Stage 1 to form sub-matrices $\left(M_{11,12,13}\right.$ $\left.M_{21,22,23}, M_{31,32,33}\right)$ from $\left(M_{1}, M_{2}, M_{3}\right)$ according to $T$ values as shown in Figure 4.

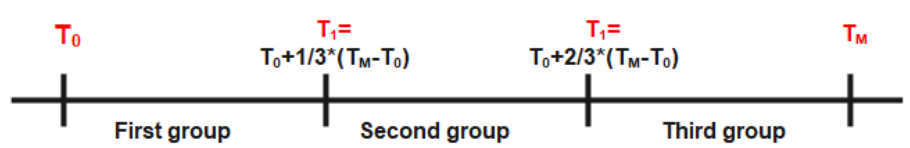

Figure 4. Sub-group formation according to $\mathrm{T}$ values.

- Third Stage

1. Rearrange the rows of the sub-matrices $\left(M_{11,12,13}, M_{21,22,23}, M_{31,32,33}\right)$ according to the values of $V_{W}$ in ascending order.

2. Follow the sub-grouping technique used in Stage 1 to form sub-matrices $\left(M_{111}, M_{112}\right.$, $\left.M_{113}, M_{121}, M_{122}, M_{123}, M_{131}, M_{132}, M_{133}, \ldots, \ldots\right)$ from $\left(M_{11,12,13}, M_{21,22,23}, M_{31,32,33}\right)$ according to $V_{W}$ values as shown in Figure 5.

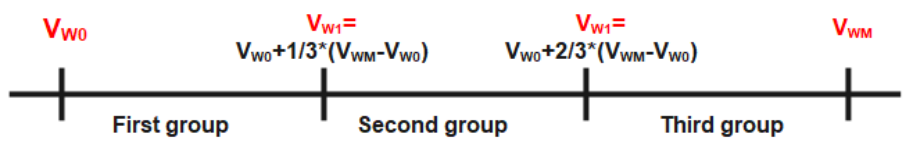

Figure 5. Sub-group formation according to $V_{W}$ values.

- Fourth Stage

Complete the same steps mentioned in the third stage on $\left(M_{111}, M_{112}, M_{113}, M_{121}\right.$, $\left.M_{122}, M_{123}, M_{131}, M_{132}, M_{133}, \ldots, \ldots\right)$ but according to the values of $L R$ as shown in Figure 6.

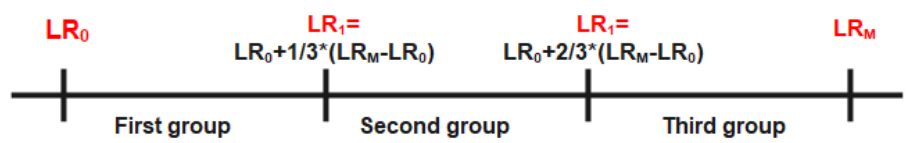

Figure 6. Sub-group formation according to $L R$ values.

After completing the four stages, there will be 81 sub-matrices produced. In each submatrix, the elements of each column have close values (small numerical range). Therefore, each sub-matrix produces one uncertainty case by determining the average value of each column value. The whole process of the proposed uncertainty case reduction is summarized in Figure 7. Also, a simplified numerical example (only two uncertainty parameters and the number of sub-groups of the uncertainty parameter values range equal to 2) is shown in Figure 8. The figure shows that data of any hour does not overlap or separate during the different stages of arrangement 


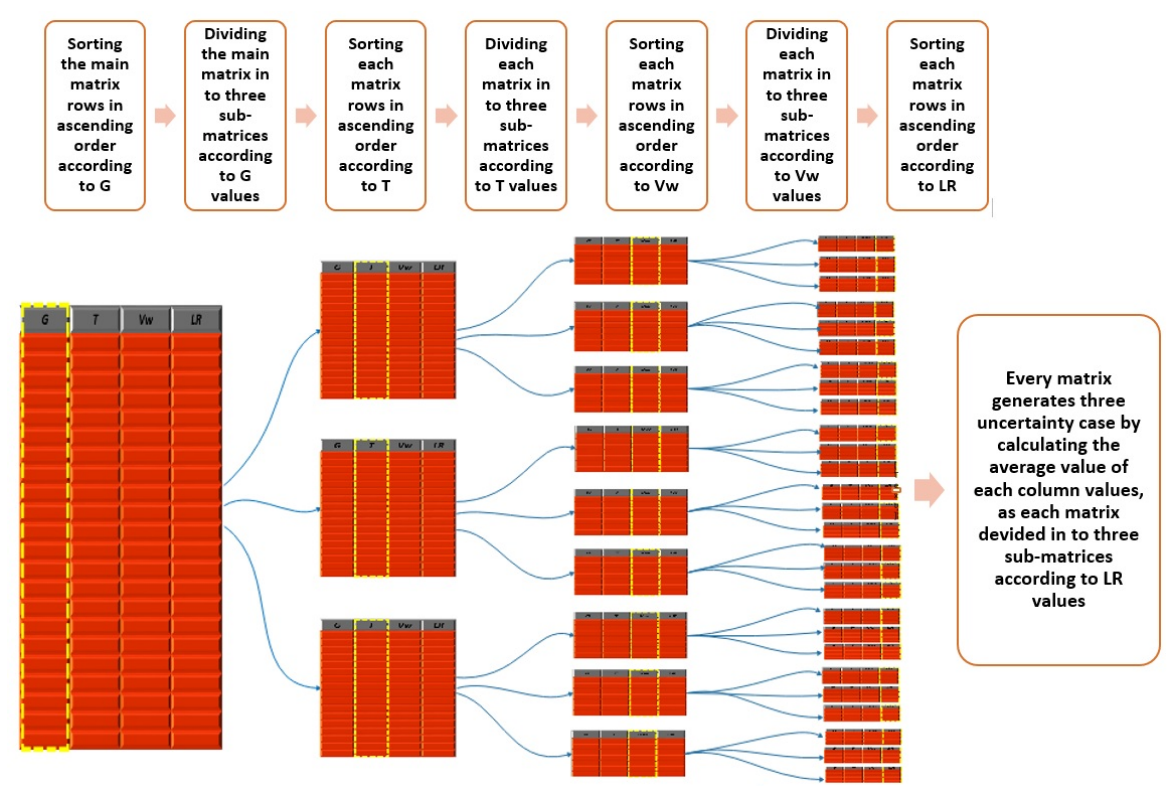

Figure 7. uncertainty Reduction criterion diagram.
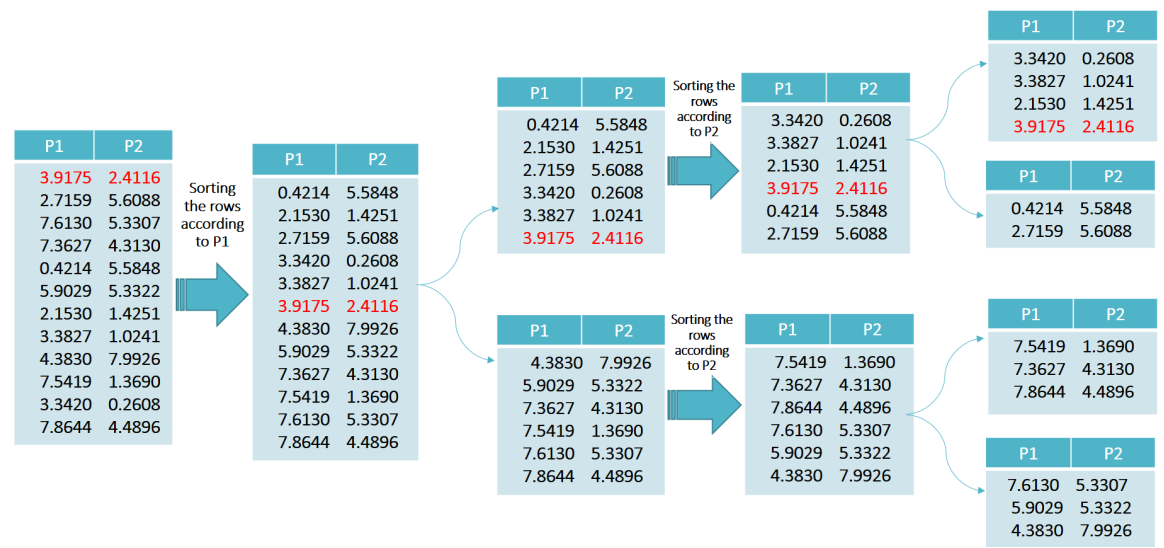

Figure 8. A numerical example for the uncertainty Reduction criterion.

\section{Implementation of the Proposed Reduction Strategy for Distribution Systems Operation}

The accuracy of the proposed reduction criterion will be tested by measuring the error ratio in calculating the total energy loss during the year and the lowest voltage and highest voltage values throughout the year, and a voltage coefficient measures the extent to which voltage values are outside the permissible limits. These errors will be calculated when different distributed RESs units are integrated into the distribution systems as follows:

\subsection{Energy Loss Error}

The actual energy loss $\left(E_{l o s s y}\right)$ can be calculated from the detailed data of the studied period 'one year in this paper' by doing load flow calculations for the system every hour in the year and summing the power loss all over the year as follows:

$$
E_{\text {lossy }}=\sum_{h r=1}^{8784} \sum i^{2} R
$$


where $i$ refers to the line current, and $R$ refers to the line resistance. The energy loss calculated from the proposed reduction method is calculated as follows:

$$
E_{\text {lossr }}=\sum_{u c=1}^{n_{u c}}\left(\sum i^{2} R\right) \times N_{h r u c}
$$

where $u c$ refers to the uncertainty case, $N_{h r u c}$ is the number of hours represented by the uncertainty case, and $n_{u c}$ is the number of uncertainty cases in the reduction criterion, which are calculated from

$$
n_{u c}=\left(N_{\text {range }}\right)^{N P}
$$

where $N_{\text {range }}$ refers to the number of sub-groups of the uncertainty parameter values range. $N P$ refers to the number of the uncertainty parameters in the problem. The energy loss error can be calculated from the following equation:

$$
E_{\text {losserror }} \%=\frac{E_{\text {lossy }}-E_{\text {lossr }}}{E_{\text {lossy }}} \times 100
$$

\subsection{The Lowest and Highest Voltage Value Errors}

The lowest voltage value $\left(V_{\text {lowest }}\right)$ error throughout the year can be calculated as follows:

$$
V_{\text {lowesterror }} \%=\frac{\min \left(V_{y}\right)-\min \left(V_{r}\right)}{\min \left(V_{y}\right)} \times 100
$$

where $V_{y}$ is the bus voltages matrix generated from load flow calculations for every hour in the year, and $V_{r}$ is the bus voltages matrix generated from load flow calculations for every uncertainty case in the reduction method. Additionally, the highest voltage value $\left(V_{\text {highest }}\right)$ error throughout the year can be calculated as follows:

$$
V_{\text {highesterror }} \%=\frac{\max \left(V_{y}\right)-\max \left(V_{r}\right)}{\max \left(V_{y}\right)} \times 100
$$

\subsection{Two-Voltages out Limits Error}

The voltage out limits coefficient measures to what extent the voltage values are outside the permissible limits $( \pm 5 \%)$. This coefficient is calculated for actual year data $\left(\operatorname{cof} f_{V_{\text {outy }}}\right)$ and for the proposed reduction criterion $\left(\operatorname{cof} f f_{V_{\text {outr }}}\right)$ as follows:

$$
\begin{gathered}
\operatorname{coff} f_{V_{\text {outy }}}=\sum_{h r=1}^{8784} \sum_{i=1}^{n_{\text {bus }}} O L I_{h r_{i}}\left(0.05-\left|1-V_{h r_{i}}\right|\right) \\
\operatorname{coff} f_{V_{\text {outr }}}=\sum_{j=1}^{n_{\text {uc }}} N_{h r u c} \times \sum_{i=1}^{n_{\text {bus }}} O L I_{j i}\left(0.05-\left|1-V_{j i}\right|\right)
\end{gathered}
$$

where

$$
O L I_{i}= \begin{cases}1 & V_{i}>1.05 \text { or } V_{i}<0.95 \\ 0 & \text { otherwise }\end{cases}
$$

where $V_{i}$ is the voltage of bus i in per unit. $O L I$ refers to the voltage out limit indicator. The voltage out limits error can be calculated from the following equation:

$$
\operatorname{coff} f_{V_{\text {outerror }}} \%=\frac{\operatorname{coff} f_{V_{\text {outy }}}-\operatorname{cof} f_{V_{\text {outr }}}}{\operatorname{coff} f_{V_{\text {outy }}}} \times 100
$$




\section{Applications}

\subsection{Description of Test Systems}

The considered test systems are an IEEE 69-bus distribution system [39] and 118-bus distribution system [40]. The total active and reactive load demands of the two systems are $3.802+j 2.694$ MVA and 22.709 + j17.04 MVA, respectively. The total power losses for the two distribution systems in the initial case are $225 \mathrm{~kW}$ and $1297.87 \mathrm{~kW}$, respectively. The system configurations are shown in Figures 9 and 10. For testing the proposed reduction strategy in the distribution system with distributed RES, the test systems have been provided with RESs plants. The integrated plants in the IEEE 69-bus and 118-bus distribution systems are listed in Table 1, respectively. The PV modules type considered in this paper is the SUNSET Poly-Crystalline model [PTSP250P-6-60], which contains 60 PV cells. The parameters of this module were estimated experimentally in [41]. The PV module parameters are listed in Table 2. Also, the considered WT parameters are listed in Table 3.

Table 1. The integrated plants in IEEE 69-bus and 118-bus distribution systems.

\begin{tabular}{ccccccccccccc}
\hline System & \multicolumn{3}{c}{ 69-Bus } & \multicolumn{7}{c}{ 118-Bus } \\
\hline Plant type & \multicolumn{2}{c}{ PV } & \multicolumn{2}{c}{ WT } & & PV & & WT \\
\hline Place & 61 & 46 & 18 & 47 & 4 & 74 & 93 & 24 & 40 & 69 \\
\hline $\begin{array}{c}\text { Nunits (PV modules or wind } \\
\text { turbines ) }\end{array}$ & 2000 & 1000 & 30 & 100 & 2000 & 1000 & 100 & 40 & 80 & 70 \\
\hline
\end{tabular}

Table 2. PV module parameters.

\begin{tabular}{cccccccc}
\hline Parameter & $I s_{1}(\mu \mathrm{A})$ & $I s_{2}(\mu \mathrm{A})$ & $R_{s}(m \Omega)$ & $R_{p}(\Omega)$ & $I_{p h_{S T C}}(A)$ & a1 & a2 \\
\hline value & 0.5593 & 23.6471 & 9.9664 & 4.3606 & 8 & 1.5 & 2 \\
\hline
\end{tabular}

Table 3. WT module parameters.

\begin{tabular}{lcccc}
\hline Parameter & $v_{c i}(\mathrm{~m} / \mathrm{s})$ & $v_{c o}(\mathrm{~m} / \mathrm{s})$ & $v_{r}(\mathrm{~m} / \mathrm{s})$ & $p_{\text {rated }}(\mathrm{KW})$ \\
\hline value & 3 & 25 & 10 & 11 \\
\hline
\end{tabular}

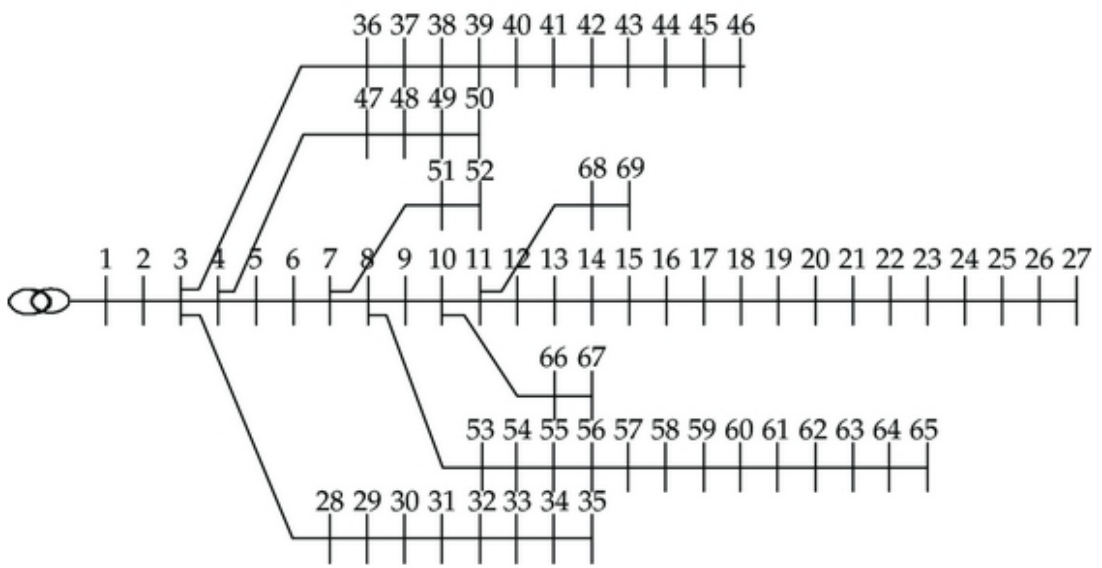

Figure 9. Single line diagram of IEEE 69-bus distribution system. 


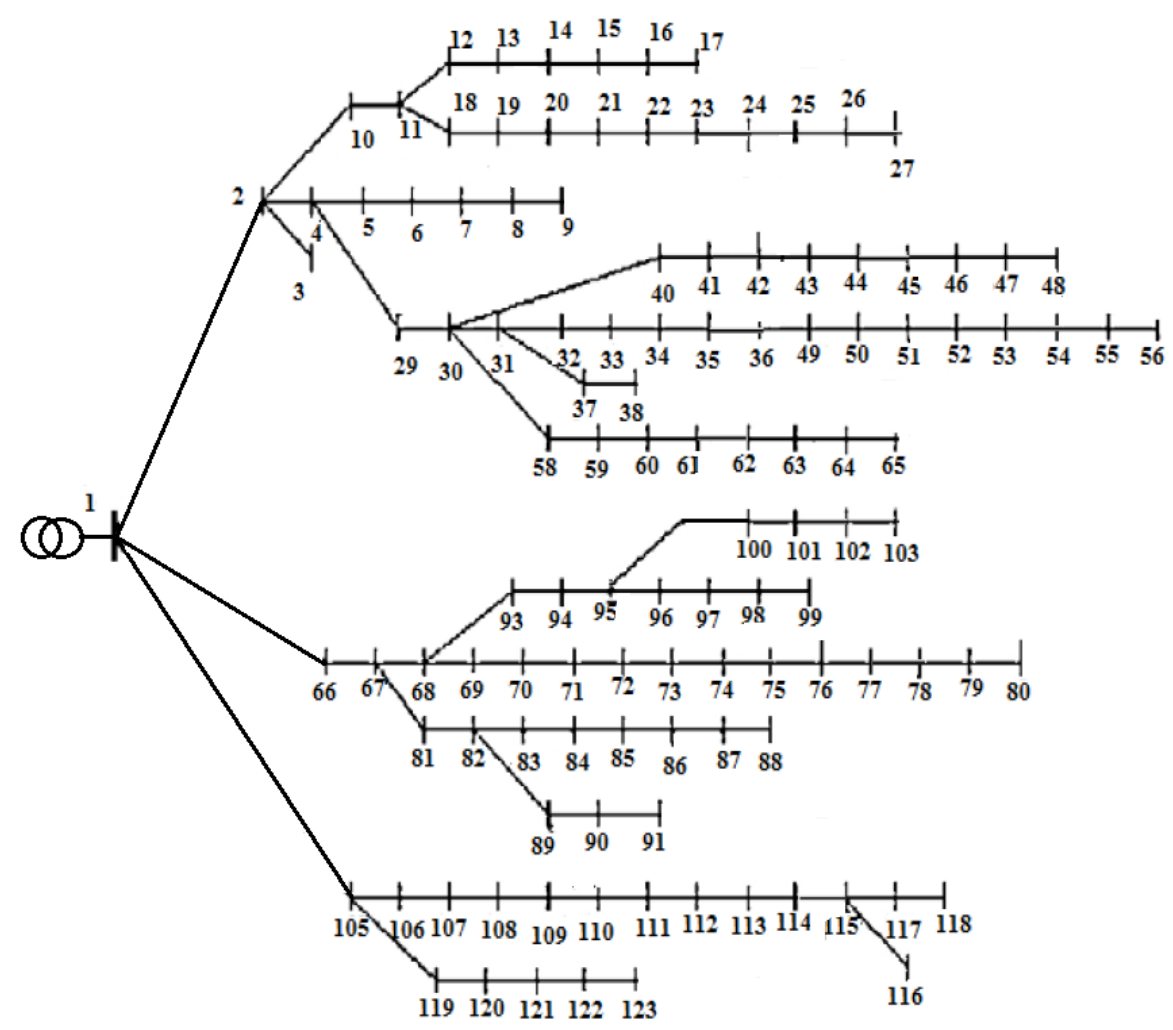

Figure 10. Single line diagram of 118-bus distribution system.

\subsection{Reduction Strategy for Uncertainty}

The hourly historical data of wind speed, solar irradiance, and ambient temperature of Cairo, Egypt, for one year (2016) are considered in this paper. Three different reduction cases use the proposed criterion to obtain the appropriate accuracy and speed.

\subsubsection{Twenty-Seven Uncertainty Cases Reduction Strategy}

In this strategy, the approximate PV modeling is considered, so that there are three uncertainty parameters $\left(\mathrm{G}, V_{W}, \mathrm{LR}\right)$. The basic data of the year will be applied to three sorting stages, 'the first, third, and fourth stages of the Proposed reduction criteria'. The uncertainty parameter value range will be divided into three numerical sub-groups, so $N_{\text {range }}$ will be equal to 3 . Thus, the number of uncertainty cases of this reduction strategy is 27 according to Equation (10). The uncertainty parameters data through the sorting stages are shown in Figure 11. By applying PV module and wind turbine equations, the output power from both sources (one PV module or one WT) in each uncertainty case could be obtained. The resulting uncertainty cases of this reduction strategy are shown in Figure 12.

\subsubsection{Sixty-Four Uncertainty Cases Reduction Strategy}

In this strategy, the approximate PV modeling is considered, so there are three uncertainty parameters, and the basic data of the year will be applied to three sorting stages as in the 27 uncertainty cases reduction strategy. However, for more accuracy, the uncertainty parameter values range will be divided into four numerical sub-groups, so $N_{\text {range }}$ will be equal to 4 . Thus, the number uncertainty cases of this reduction strategy is 64 . The uncertainty parameters data through the sorting stages are shown in Figure 13. Additionally, the resulting uncertainty cases of this reduction strategy are shown in Figure 14. 

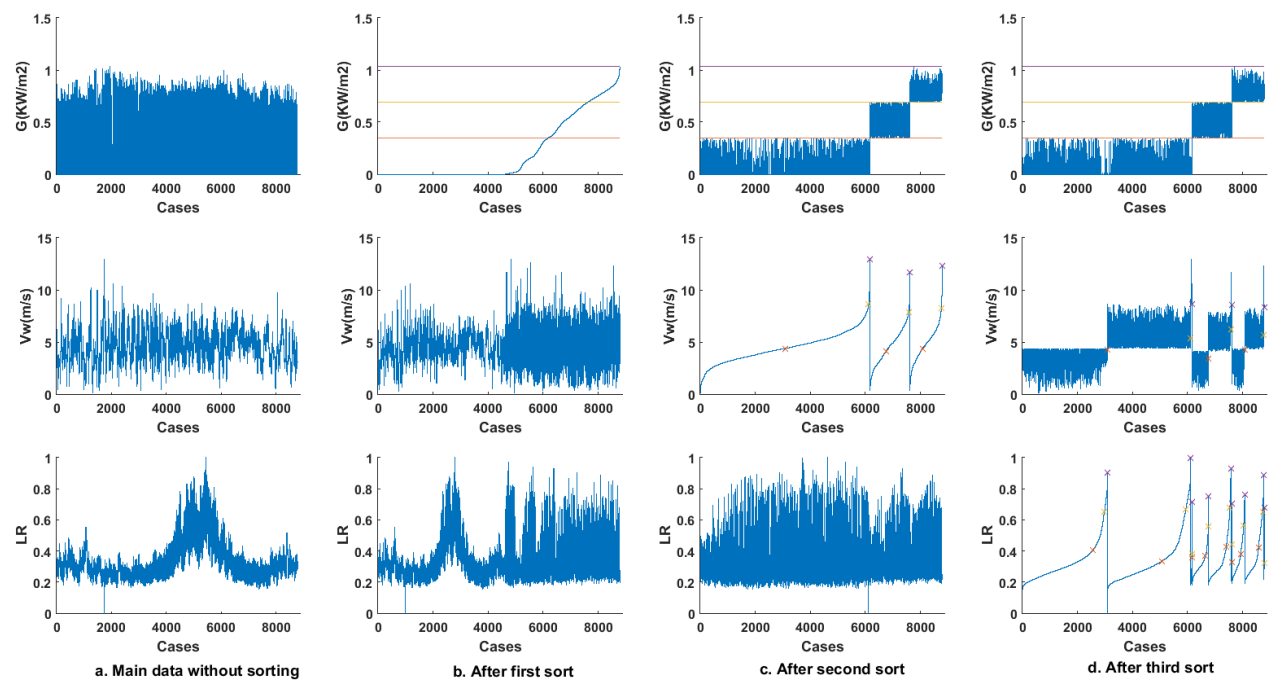

Figure 11. One-year data through the sorting stages in the 27 uncertainty cases reduction strategy.

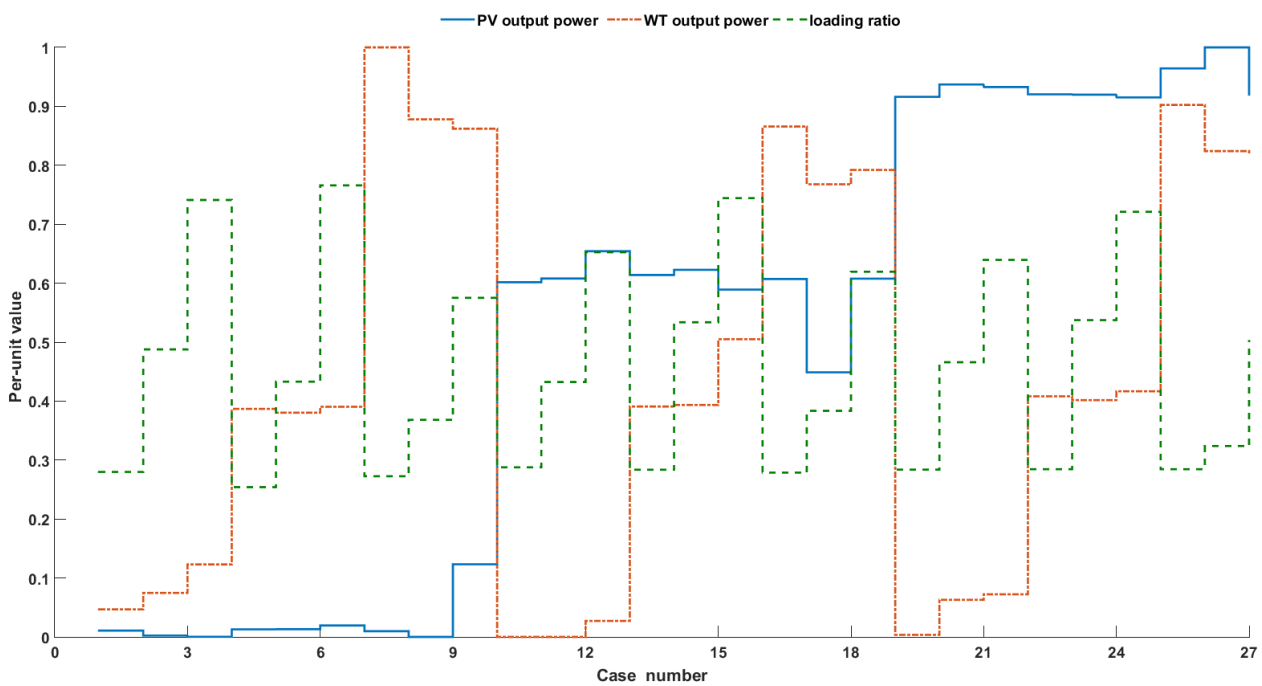

Figure 12. Resulting uncertainty cases of the 27 uncertainty cases reduction strategy.
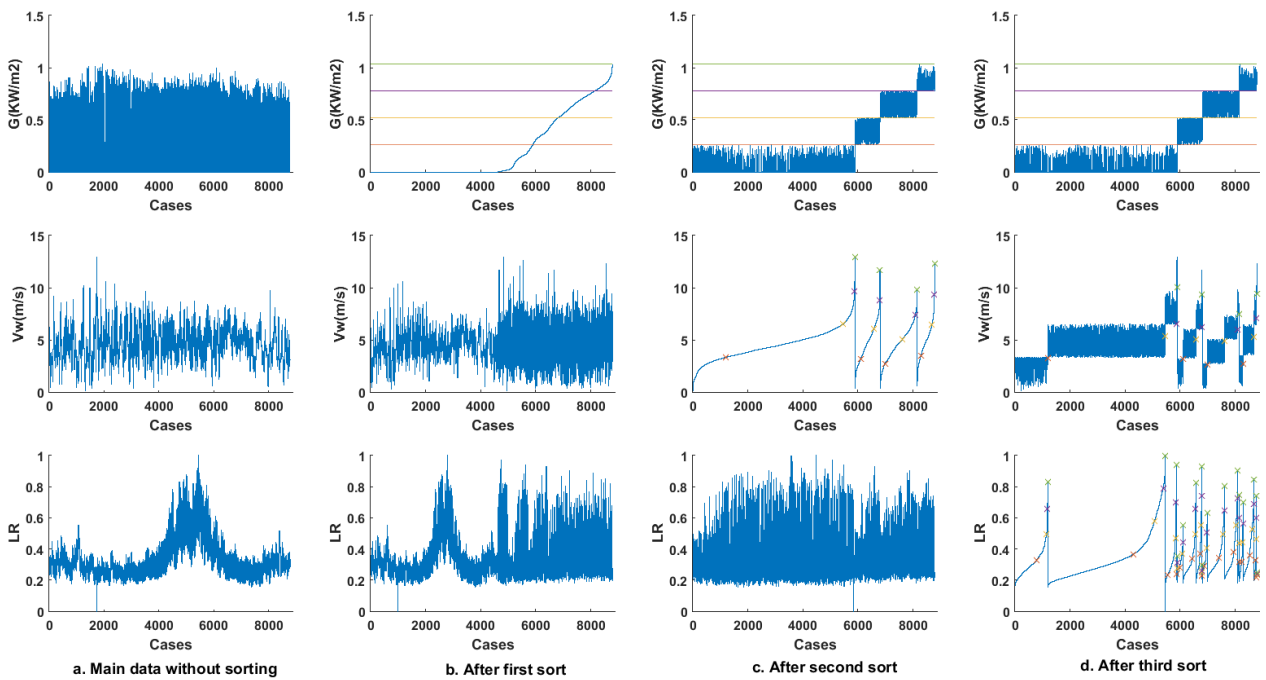

Figure 13. One-year data through the sorting stages in the 64 uncertainty cases reduction strategy. 


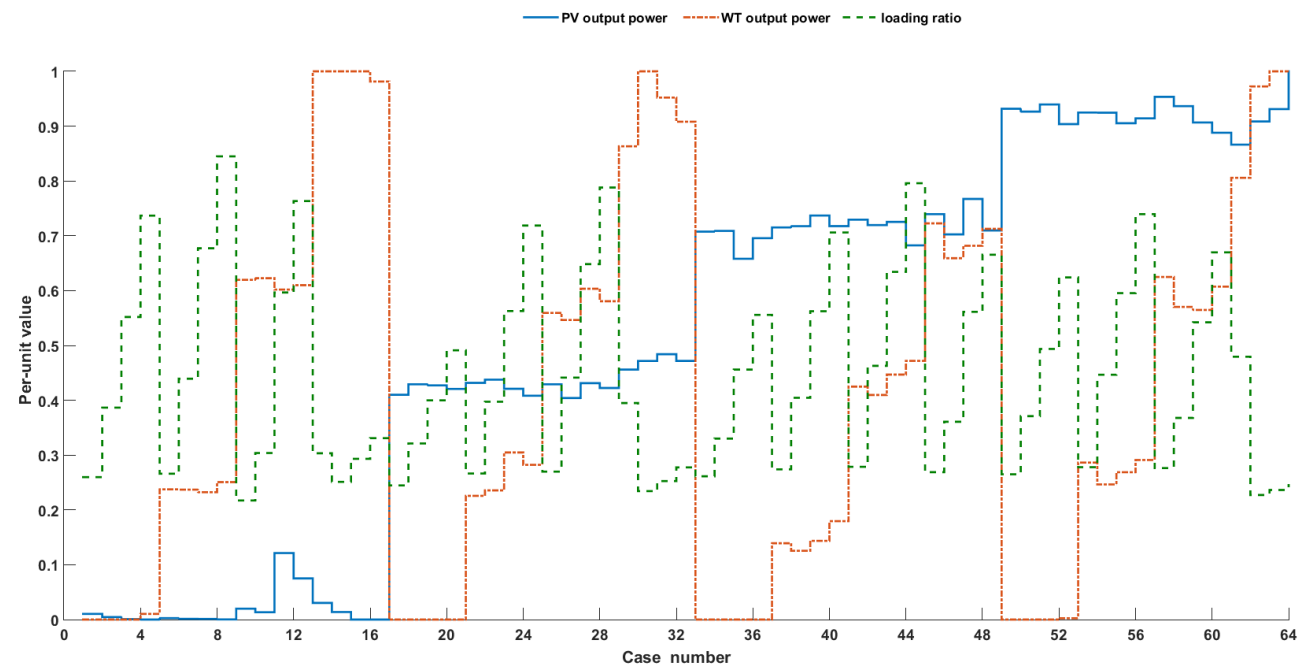

Figure 14. Resulting uncertainty cases of the 64 uncertainty cases reduction strategy.

\subsubsection{Eighty-One Uncertainty Cases Reduction Strategy}

In this strategy, the accurate PV modeling is considered. Thus, there are four uncertainty parameters $\left(\mathrm{G}, \mathrm{T}, V_{\mathrm{W}}, \mathrm{LR}\right)$, and the basic data of the year will be applied to all stages of the proposed reduction criterion. However, for reducing the system planning calculation speed, The uncertainty parameter value range will be divided into three numerical subgroups, so $N_{\text {range }}$ will be equal to 3 . Thus, the number of uncertainty cases of this reduction strategy is 81 . The uncertainty parameters data through the sorting stages are shown in Figure 15. Additionally, the resulting uncertainty cases of this reduction strategy are shown in Figure 16.
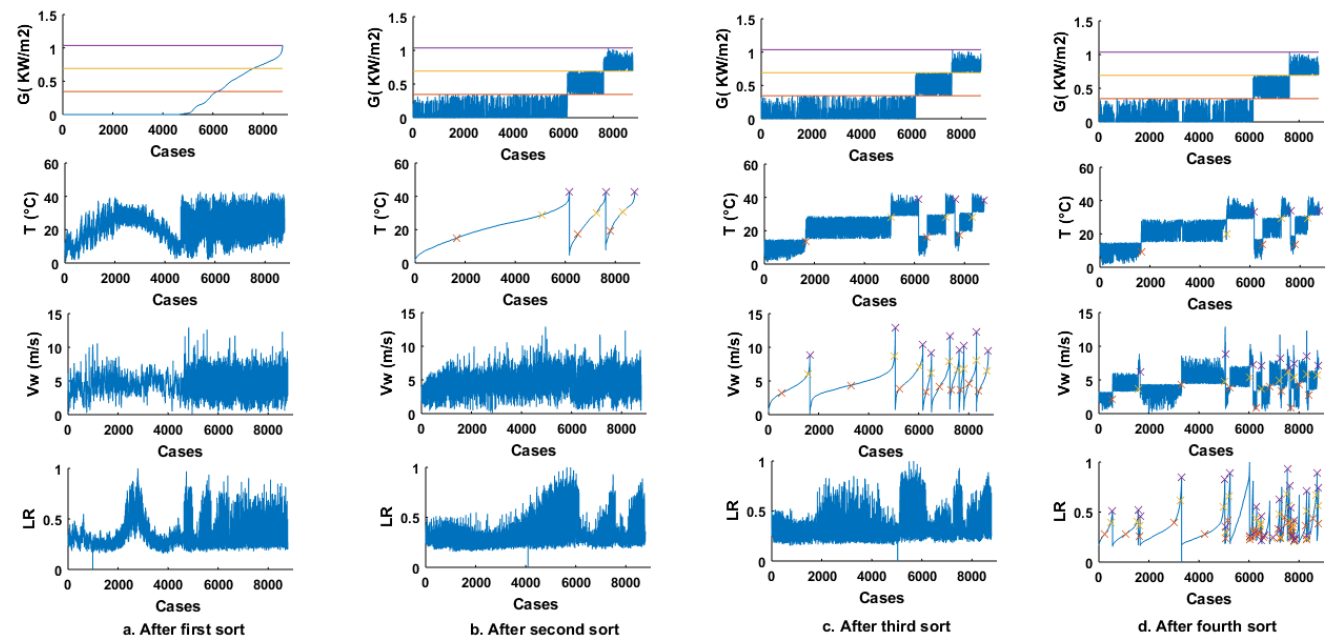

Figure 15. One-year data through the sorting stages in the 81 uncertainty cases reduction strategy.

\subsection{Applications to Distribution Systems}

The resulting uncertainty case reduction strategies have been applied to the RESs penetrated test systems for calculating the total energy loss throughout the year, the lowest voltage and highest voltage values throughout the year, and the voltage out limits coefficient. Additionally, the detailed data of the year have been applied to the same problem. Moreover, the errors between each uncertainty case reduction strategy and the detailed data of the year have been calculated as shown in Tables 4 and 5. From the results, it is obtained that the lowest voltage values error does not exceed $4 \%$ in all reduction strategies. The highest voltage values error for all reduction strategies is very small and does not exceed $1 \%$. Additionally, the energy losses over the whole year error does not 
exceed 5\%. However, the error in voltage out limits coefficients is considered relatively large as it reached $17.8 \%$ in the 27 cases reduction strategy for 69 bus system. This is logical since the calculation of this coefficient depends on the summation of the system bus voltages over the whole year, and therefore if there is a percentage error in the voltage of each bus, the errors of all buses will be accumulated. Thus, the total error becomes large. This also explains the increase in this error by increasing the number of system buses as shown in the 64 and 81 cases reduction strategies. The 27 cases reduction strategy has error values larger than the 64 and 81 cases reduction strategies, but this strategy is characterized by the lowest uncertainty cases number. Thus, it is recommended in optimal planning studies as it is fast in testing an operation case over the whole year. The 64 and 81 cases reduction strategies compete for the lowest errors, as each one has its advantages. The 81 cases reduction strategy is more accurate in calculating the output of PV plants than the 64 cases reduction strategy. Moreover, the 81 cases reduction strategy is more representative than the 64 cases reduction strategy in the uncertainty parameter values throughout the year, as it divided the parameter values range into four sub-groups. Thus, the 81 cases reduction strategy is the best for the 69-bus system. However, in the 118-bus, the number of PV and WT units increases, where the summation of WT-rated power is larger than the summation of PV-rated power. Thus, in the 118-bus system, the 64 cases reduction strategy is the best. From all the previous results, it is obtained that the proposed cases reduction strategies in RESs uncertainty modeling in distribution systems are very effective and have an acceptable level of accuracy.

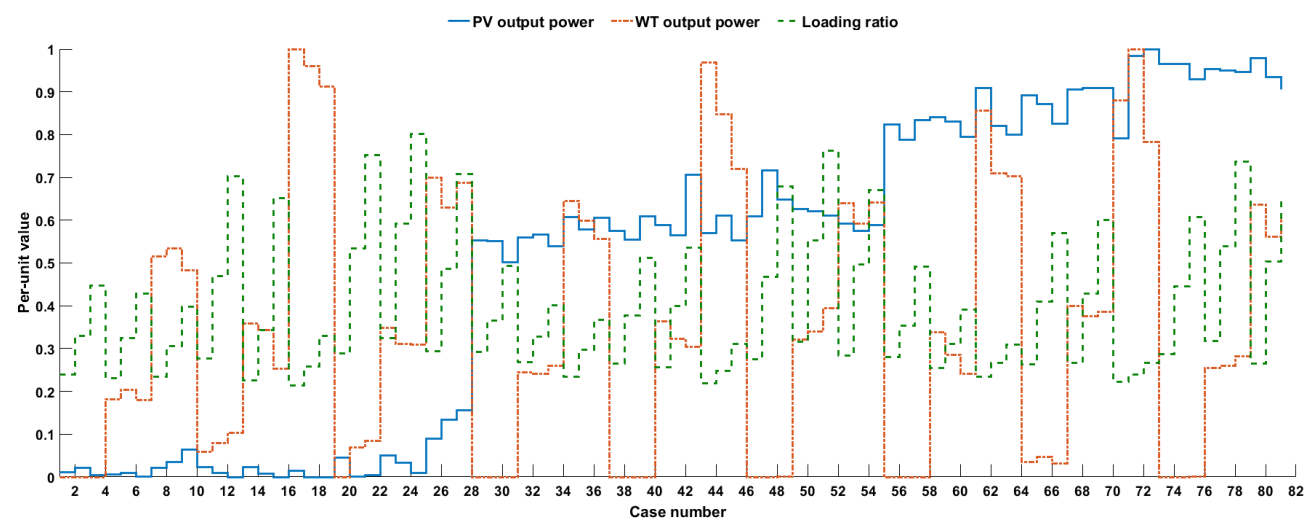

Figure 16. Resulting uncertainty cases of the 81 uncertainty cases reduction strategy.

Table 4. The proposed reduction strategy results in distribution systems operation.

\begin{tabular}{cccccc}
\hline \multirow{2}{*}{ System } & $\begin{array}{c}\text { Modeling } \\
\text { Method }\end{array}$ & $\boldsymbol{v}_{\text {lowest }}$ & $\boldsymbol{v}_{\text {highest }}$ & $\boldsymbol{E}_{\text {loss }}$ & coff $f_{\text {Vout }}$ \\
\hline \multirow{3}{*}{ 69-bus } & All year data & 0.8784 & 1.0446 & $2.5543 \times 10^{8}$ & 108.1319 \\
\cline { 2 - 6 } & 81 cases & 0.9063 & 1.0445 & $2.4597 \times 10^{8}$ & 99.7397 \\
\cline { 2 - 6 } & 27 cases & 0.9121 & 1.0368 & $2.6527 \times 10^{8}$ & 88.7837 \\
\cline { 2 - 6 } & 64 cases & 0.8995 & 1.0468 & $2.6776 \times 10^{8}$ & 97.3506 \\
\hline \multirow{2}{*}{ 118-bus } & All year data & 0.8760 & 1.0286 & $1.2142 \times 10^{9}$ & 217.2986 \\
\cline { 2 - 6 } & 81 cases & 0.9058 & 1.0277 & $1.1743 \times 10^{9}$ & 193.3500 \\
\hline 2 2-6 & 27 cases & 0.9091 & 1.0228 & $1.1663 \times 10^{9}$ & 180.8850 \\
\hline
\end{tabular}


Table 5. Resulting errors after testing the proposed reduction strategies in distribution systems operation.

\begin{tabular}{|c|c|c|c|c|c|}
\hline System & $\begin{array}{l}\text { Modeling } \\
\text { Method }\end{array}$ & $v_{\text {lowesterror }}$ & $v_{\text {highesterror }}$ & $E_{\text {losserror }}$ & cof $f_{\text {Vouerror }}$ \\
\hline \multirow{4}{*}{ 69-bus } & All year data & - & - & - & - \\
\hline & 81 cases & 3.1742 & 0.0161 & 3.7059 & 7.7610 \\
\hline & 27 cases & 3.8372 & 0.7440 & 3.8518 & 17.8932 \\
\hline & 64 cases & 2.3998 & 0.2108 & 4.8266 & 9.9705 \\
\hline \multirow{4}{*}{ 118-bus } & All year data & - & - & - & - \\
\hline & 81 cases & 3.4042 & 0.0861 & 3.2889 & 11.0210 \\
\hline & 27 cases & 3.7788 & 0.5623 & 3.9425 & 16.7574 \\
\hline & 64 cases & 2.5230 & 0.0262 & 3.0167 & 11.5163 \\
\hline
\end{tabular}

\section{Conclusions}

In this paper, an efficient new criterion is proposed for modeling system load and RESs uncertainties in distribution systems. Two types of RESs are considered (PV and WT). Three different reduction case strategies are applied to the new criterion to obtain the appropriate accuracy and speed. The proposed reduction strategies lead to a $99 \%$ reduction in the uncertainty cases for one year, which is sufficient for effective modeling with an acceptable level of accuracy. The proposed reduction strategies are tested on IEEE 96- and IEEE 118-bus systems. The results verify the effectiveness of the proposed methods in RESs uncertainty modeling in distribution systems with an acceptable level of accuracy, as the lowest voltage values error does not exceed $4 \%$, the highest voltage values error does not exceed $1 \%$, and the energy losses error does not exceed $5 \%$.

Author Contributions: E.S.A., R.A.E.-S. and A.A.A.E.-E.; methodology, E.S.A., R.A.E.-S. and A.A.A.E.E.; validation, M.T.-V. and S.K.; formal analysis, M.T.-V. and S.K.; investigation, E.S.A., R.A.E.-S. and A.A.A.E.-E.; resources, M.T.-V. and S.K.; writing-original draft preparation, E.S.A., R.A.E.-S. and A.A.A.E.-E.; writing-review and editing, M.T.-V. and S.K.; visualization, E.S.A., R.A.E.-S. and A.A.A.E.-E. All authors have read and agreed to the published version of the manuscript.

Funding: This research received no external funding.

Institutional Review Board Statement: Not applicable.

Informed Consent Statement: Not applicable.

Data Availability Statement: The data presented in this study are available on request from the corresponding author.

Acknowledgments: The authors thank the support of the National Research and Development Agency of Chile (ANID), ANID/Fondap/15110019.

Conflicts of Interest: The authors declare no conflict of interest.

\section{References}

1. Gao, H.; Xu, S.; Liu, Y.; Wang, L.; Xiang, Y.; Liu, J. Decentralized optimal operation model for cooperative microgrids considering renewable energy uncertainties. Appl. Energy 2020, 262, 114579. [CrossRef]

2. Yang, D.; Jiang, C.; Cai, G.; Yang, D.; Liu, X. Interval method based optimal planning of multi-energy microgrid with uncertain renewable generation and demand. Appl. Energy 2020, 277, 115491. [CrossRef]

3. Ali, E.S.; El-Sehiemy, R.A.; El-Ela, A.; Adel, A.; Mahmoud, K.; Lehtonen, M.; Darwish, M.M. An Effective Bi-Stage Method for Renewable Energy Sources Integration into Unbalanced Distribution Systems Considering Uncertainty. Processes $2021,9,471$. [CrossRef]

4. Elsakaan, A.A.; El-Sehiemy, R.A.; Kaddah, S.S.; Elsaid, M.I. Optimal economic-emission power scheduling of RERs in MGs with uncertainty data. IET Gener. Transm. Distrib. 2020, 14, 37-52. [CrossRef] 
5. Xiaohui, Z.; Wenbo, G.; Jiaqing, Z. Decentralized Economic Dispatching of Multi-Micro Grid Considering Wind Power and Photovoltaic Output Uncertainty. IEEE Access 2021, 9, 104093-104103. [CrossRef]

6. Shaheen, A.M.; Elattar, E.E.; El-Sehiemy, R.A.; Elsayed, A.M. An improved sunflower optimization algorithm-based Monte Carlo simulation for efficiency improvement of radial distribution systems considering wind power uncertainty. IEEE Access 2020, 9, 2332-2344. [CrossRef]

7. Abou El-Ela, A.A.; El-Sehiemy, R.A.; Ali, E.S.; Kinawy, A.M. Minimisation of voltage fluctuation resulted from renewable energy sources uncertainty in distribution systems. IET Gener. Transm. Distrib. 2019, 13, 2339-2351. [CrossRef]

8. Sakr, W.; Abd el Ghany, H.A.; EL-Sehiemy, R.A.; Azmy, A.M. A Day-ahead Optimal RERs Scheduling Approach for Virtual Power Plants Considering Different Loading Conditions. In Proceedings of the 2019 21st International Middle East Power Systems Conference (MEPCON), Cairo, Egypt, 17-19 December 2019; pp. 784-789.

9. Zio, E.; Delfanti, M.; Giorgi, L.; Olivieri, V.; Sansavini, G. Monte Carlo simulation-based probabilistic assessment of DG penetration in medium voltage distribution networks. Int. J. Electr. Power Energy Syst. 2015, 64, 852-860. [CrossRef]

10. Aien, M.; Rashidinejad, M.; Fotuhi-Firuzabad, M. On possibilistic and probabilistic uncertainty assessment of power flow problem: A review and a new approach. Renew. Sustain. Energy Rev. 2014, 37, 883-895. [CrossRef]

11. Soroudi, A.; Ehsan, M. A possibilistic-probabilistic tool for evaluating the impact of stochastic renewable and controllable power generation on energy losses in distribution networks-A case study. Renew. Sustain. Energy Rev. 2011, 15, 794-800. [CrossRef]

12. Bakhtiari, H.; Zhong, J.; Alvarez, M. Predicting the stochastic behavior of uncertainty sources in planning a stand-alone renewable energy-based microgrid using Metropolis-coupled Markov chain Monte Carlo simulation. Appl. Energy 2021, $290,116719$. [CrossRef]

13. Zhao, Q.; Wang, P.; Goel, L.; Ding, Y. Evaluation of nodal reliability risk in a deregulated power system with photovoltaic power penetration. IET Gener. Transm. Distrib. 2013, 8, 421-430. [CrossRef]

14. Arabali, A.; Ghofrani, M.; Etezadi-Amoli, M.; Fadali, M.S. Stochastic performance assessment and sizing for a hybrid power system of solar/wind/energy storage. IEEE Trans. Sustain. Energy 2013, 5, 363-371. [CrossRef]

15. Hong, Y.Y.; Luo, Y.F. Optimal VAR control considering wind farms using probabilistic load-flow and gray-based genetic algorithms. IEEE Trans. Power Deliv. 2009, 24, 1441-1449. [CrossRef]

16. Hong, Y.Y.; Lin, F.J.; Lin, Y.C.; Hsu, F.Y. Chaotic PSO-based VAR control considering renewables using fast probabilistic power flow. IEEE Trans. Power Deliv. 2013, 29, 1666-1674. [CrossRef]

17. Moeini-Aghtaie, M.; Abbaspour, A.; Fotuhi-Firuzabad, M. Incorporating large-scale distant wind farms in probabilistic transmission expansion planning-Part I: Theory and algorithm. IEEE Trans. Power Syst. 2012, 27, 1585-1593. [CrossRef]

18. Bie, Z.; Sun, C.; Ning, G.; Gao, Y. Adequacy evaluation of generating system recognizing random fuzzy wind speed. In Proceedings of the 2013 IEEE PES Asia-Pacific Power and Energy Engineering Conference (APPEEC), Hong Kong, China, 8-13 December 2013; pp. 1-5.

19. Soroudi, A. Possibilistic-scenario model for DG impact assessment on distribution networks in an uncertain environment. IEEE Trans. Power Syst. 2012, 27, 1283-1293. [CrossRef]

20. Ben-Tal, A.; El Ghaoui, L.; Nemirovski, A. Robust Optimization; Princeton University Press: Princeton, NJ, USA, 2009.

21. Lorca, A.; Sun, X.A. Adaptive robust optimization with dynamic uncertainty sets for multi-period economic dispatch under significant wind. IEEE Trans. Power Syst. 2014, 30, 1702-1713. [CrossRef]

22. Atwa, Y.M.; El-Saadany, E.F. Probabilistic approach for optimal allocation of wind-based distributed generation in distribution systems. IET Renew. Power Gener. 2011, 5, 79-88. [CrossRef]

23. Rabiee, A.; Mohseni-Bonab, S.M. Maximizing hosting capacity of renewable energy sources in distribution networks: A multi-objective and scenario-based approach. Energy 2017, 120, 417-430. [CrossRef]

24. Capitanescu, F.; Ochoa, L.F.; Margossian, H.; Hatziargyriou, N.D. Assessing the potential of network reconfiguration to improve distributed generation hosting capacity in active distribution systems. IEEE Trans. Power Syst. 2014, 30, 346-356. [CrossRef]

25. Ehsan, A.; Cheng, M.; Yang, Q. Scenario-based planning of active distribution systems under uncertainties of renewable generation and electricity demand. CSEE J. Power Energy Syst. 2019, 5, 56-62. [CrossRef]

26. Chen, B.; Wang, J.; Wang, L.; He, Y.; Wang, Z. Robust optimization for transmission expansion planning: Minimax cost vs. minimax regret. IEEE Trans. Power Syst. 2014, 29, 3069-3077. [CrossRef]

27. Taha, A.F.; Bazrafshan, M.; Nugroho, S.A.; Gatsis, N.; Qi, J. Robust control for renewable-integrated power networks considering input bound constraints and worst case uncertainty measure. IEEE Trans. Control Netw. Syst. 2019, 6, 1210-1222. [CrossRef]

28. Zakaria, A.; Ismail, F.B.; Lipu, M.H.; Hannan, M.A. Uncertainty models for stochastic optimization in renewable energy applications. Renew. Energy 2020, 145, 1543-1571. [CrossRef]

29. Adefarati, T.; Bansal, R. Reliability and economic assessment of a microgrid power system with the integration of renewable energy resources. Appl. Energy 2017, 206, 911-933. [CrossRef]

30. Chenouard, R.C.; El-Sehiemy, R.A. An interval branch and bound global optimization algorithm for parameter estimation of three photovoltaic models. Energy Convers. Manag. 2020, 205, 112400. [CrossRef]

31. El-Dabah, M.A.; El-Sehiemy, R.; Becherif, M.; Ebrahim, M.A. Parameter estimation of triple diode photovoltaic model using an artificial ecosystem-based optimizer. Int. Trans. Electr. Energy Syst. 2021, 13, e13043. [CrossRef]

32. Said, M.S.; Shaheen, A.M.; Ginidi, A.R.; El-Sabbe, A.E. Estimating Parameters of Photovoltaic Models Using Accurate Turbulent Flow of Water Optimizer. Processes 2021, 9, 627. [CrossRef] 
33. Abaza, A.; Fawzy, A.; El-Sehiemy, R.A.; Alghamdi, A.S.; Kamel, S. Sensitive reactive power dispatch solution accomplished with renewable energy allocation using an enhanced coyote optimization algorithm. Ain Shams Eng. J. 2021, 12, 1723-1939. [CrossRef]

34. Ginidi, R.A.; Shaheen, A.M.; Ginidi, A.R.; El-Sehiemy, R.A.; Elattar, R.A. Supply demand optimization algorithm for parameter extraction of various solar cell models. Energy Rep. 2021, 7, 5772-5794. [CrossRef]

35. Bayoumi, A.S.; El-Sehiemy, R.A.; Mahmoud, K.; Lehtonen, M.; Darwish, M.M. Assessment of an improved three-diode against modified two-diode patterns of MCS solar cells associated with soft parameter estimation paradigms. Appl. Sci. 2021, 11, 1055. [CrossRef]

36. Zaky, A.A.; Ibrahim, M.N.; Rezk, H.; Christopoulos, E.; El Sehiemy, R.A.; Hristoforou, E.; Kladas, E.; Sergeant, P.; Falaras, P. Energy efficiency improvement of water pumping system using synchronous reluctance motor fed by perovskite solar cells. Int. J. Energy Res. 2020, 44, 11629-11642. [CrossRef]

37. Oliva, D.; Abd El Aziz, M.; Hassanien, A.E. Parameter estimation of photovoltaic cells using an improved chaotic whale optimization algorithm. Appl. Energy 2017, 200, 141-154. [CrossRef]

38. Ramadan, A.R.; Ebeed, M.E.; Kamel, S.K.; Nasrat, L.N. Optimal allocation of renewable energy resources considering uncertainty in load demand and generation. In Proceedings of the 2019 IEEE Conference on Power Electronics and Renewable Energy (CPERE), Aswan, Egypt, 23-25 October 2019; pp. 124-128.

39. Abbas, A.S.; El-Sehiemy, R.A.; El-Ela, A.; Ali, E.S.; Mahmoud, K.; Lehtonen, M.; Darwish, M.M. Optimal Harmonic Mitigation in Distribution Systems with Inverter Based Distributed Generation. Appl. Sci. 2021, 11, 774. [CrossRef]

40. Bai, L.; Li, F.; Cui, H.; Jiang, T.; Sun, H.; Zhu, J. Interval optimization based operating strategy for gas-electricity integrated energy systems considering demand response and wind uncertainty. Appl. Energy 2016, 167, 270-279. [CrossRef]

41. Waly, H.M.; Azazi, H.Z.; Osheba, D.S.; El-Sabbe, A.E. Parameters extraction of photovoltaic sources based on experimental data. IET Renew. Power Gener. 2019, 13, 1466-1473. [CrossRef] 